\title{
Of Dragons and Geoengineering: Rethinking Elemental Media
}

Yuriko Furuhata

Keywords: chemistry, alchemy, computation, cosmology, philosophy, weather control, elemental media

https://doi.org/10.1525/001c.10797

\section{INTRODUCTION}

Dragons help ventilate the air in Hong Kong. Many of the city's high-rise apartment complexes and skyscrapers have gaping holes in their middle sections. In accordance with local lore and the feng shui (literally "wind and water") principle of not cutting off good energy flows, these holes let mythical dragons fly through the buildings (figure 1). It turns out that these stunning architectural features also have the pragmatic effects of increasing air ventilation and creating breezeways. Letting high-rise buildings breathe through these dragon holes is one way to facilitate the external movement of the tropical air and create an optimal "wind environment" in Hong Kong's densely built urban space, a place where cosmology and engineering come together (Lo 2018; Keegan 2018; Chinese University of Hong Kong, Department of Architecture 2005).

As John Durham Peters (2016, 3-4) argues, rethinking cultural techniques of controlling natural elements like wind and air from the standpoint of media studies requires a philosophy of elements. The Greek tradition of classical elements-earth, water, air, and fire-invoked by Peters provides one such framework. But these feng shui dragons slip through the epistemological grid of Greek elemental philosophy. Instead they follow the Chinese philosophy of five elements, or, more precisely, the five elemental phases: wood, fire, earth, metal, and water. In the following speculative provocation that reflects on the nexus between media and environment, I will argue that we need to expand the referential framework of "elements" beyond ancient Greece in order to productively complicate the geopolitics of elemental philosophy, and, by extension, that of elemental media.

\footnotetext{
* Yuriko Furuhata is Associate Professor and William Dawson Scholar of Cinema and Media History in the Department of East Asian Studies and an associate member of the Department of Art History and Communication Studies at McGill University. She is the author of Cinema of Actuality: Japanese Avant-Garde Filmmaking in the Season of Image Politics (Duke University Press, 2013). She is currently finalizing a book, Atmospheric Control: A Transpacific Genealogy of Climatic Media, which traces the technological, institutional, and geopolitical connections between Japan and the United States that led to the development of artificial fog, weather control, cybernetic environments, Metabolic architecture, and networked computing during the Cold War period.
} 


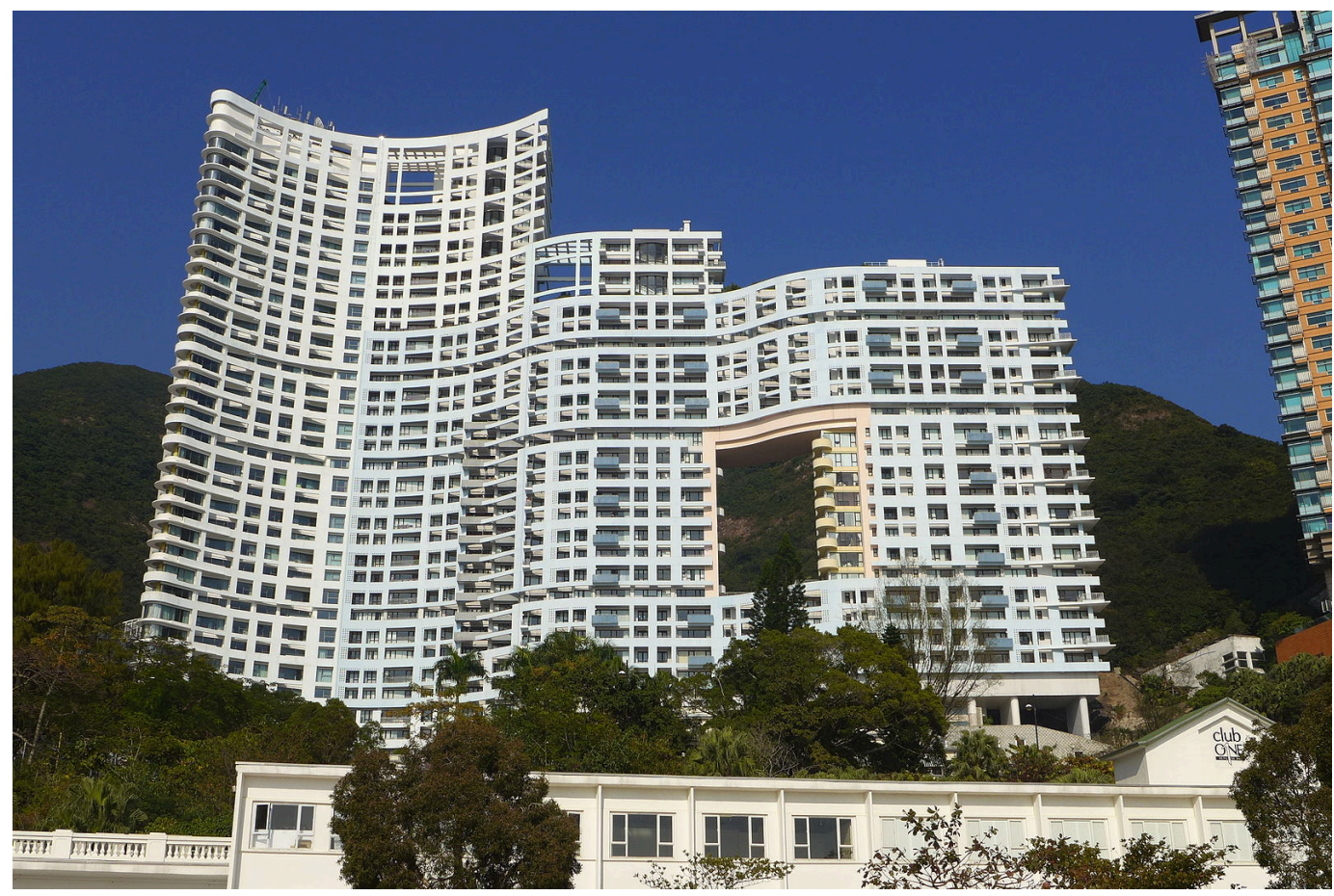

Figure 1: The Repulse Bay

Image courtesy of Wing1990hk. Creative Commons Attribution 3.0. https://creativecommons.org/licenses/by/3.0/deed.en.

\section{PHILOSOPHIES OF ELEMENTAL MEDIA}

Wood and metal are two elements conspicuously missing from the classical "Western" philosophy of four elements, though they are crucial components of the "Eastern" philosophy of five phases (wu xing in Chinese, gogyō in Japanese). Central too are the complementary dynamic cycles of interaction among these five phases; one is a cycle of generation, and the other is a cycle of subjugation. ${ }^{1}$ For instance, earth generates metal while metal subjugates wood. Although these cycles of elemental phases cosmologically relate to other organizational orders, such as the seasons, directions, colors, and body parts, we can also grasp the relational dynamics of these phases through mundane cultural techniques like mining (an earth-metal interaction) and woodcutting (a metal-wood interaction) (Yoshino 1983, 27-29).

Often combined with the Taoist cosmological principles of divination-namely the eight trigrams that represent heaven, lake, fire, thunder, wind, water, mountain, and earth - this philosophy of five elemental phases has influenced various folk practices, including the geomantic art of feng shui in East Asia. In Japan, some of the lingering folk rituals to calm strong winds involve hanging iron sickles on tree branches. This practice follows the

\footnotetext{
1 As Nicole Starosielski (2019) argues in "The Elements of Media Studies," her contribution to this stream, elements are never static "things"; they are always already "processual." Special thanks go to Brent Lin for his suggestions on feng shui and alchemy, and to Marc Steinberg for his feedback on this issue.
} 
causal logic of the five phases wherein metal conquers wood. And according to the cosmological principles of the eight trigrams, wood is an element to which wind and thunder belong (Yoshino 1983, 144-50). From ventilating dragon holes to wind-conquering iron sickles, what lies beneath these enchanted techniques of elemental control, I suggest, is a desire to manipulate the environment by generating breezes in one case and by halting stormy winds in the other. In short, these techniques are ritualized forms of weather control.

The epistemological and cosmological assumptions behind these techniques, however, may not be obvious if we were to approach them through the lens of the Greek philosophy of classical elements. We need to enlist the Chinese philosophy of five elemental phases to grasp how these enchanted techniques of weather control relate to our understanding of media. Here, it is helpful to turn to Bernhard Siegert's definition of media as cultural techniques. Media (such as the door) provide the technical conditions of possibility for the operation of the symbolic separation between nature and culture, inside and outside, sacred and profane, and other binary distinctions that structure our daily life (Siegert 2015, 13-14).

In a predictably post-structuralist manner, Siegert argues that these binary symbolic distinctions are constantly undone through the intermediary cultural techniques of media themselves. But a useful takeaway from Siegert's account of cultural techniques is that the technical operation of media is both material and symbolic. The door as media physically lets something or someone pass through it, as much as it symbolically demarcates the inside from the outside (Siegert 2015, 193). The cultural significance of the dual operation of circulation and demarcation performed by the door as media, however, differs locally and historically. We need only think of the dragons and the air that both pass through the ventilating holes on high-rise buildings. Unlike the air, however, the cosmological movement of the dragons' passage is legible only through the mediation of Chinese elemental philosophy and feng shui principles.

\section{CONTROLLING THE WEATHER}

As attention increasingly turns to the elemental within theories of media and mediation, we need to be aware of which elements (and groups of elements) we media theorists are referring to. We may begin, then, by asking which lineages of knowledge and techniques of controlling the environment have been taken for granted and which others have been ignored within media studies, and why that might be the case. This is not to say we should necessarily construct an alternative genealogy_say, a purely "Eastern" genealogy of elemental media based on the philosophy of five phases-but we should complicate our understanding of the elements and thereby of elemental media. In so doing, we may also fold geopolitics back into our discussion of media as cultural 
techniques of controlling the environment-something glaringly absent from accounts such as Siegert's anthropologically inflected yet culturally Eurocentric media theory.

Let me return to the practice of weather control to reflect on this geopolitical complexity. Dragon holes and iron sickles, I argue, are enchanted examples of microclimatic control. The technique of cloud seeding, in contrast, is their nonenchanted counterpart. At first glance, one appears mythical and the other scientific. Nonetheless, operating within the different epistemological framework of atmospheric science and chemistry, contemporary practices of weather control also revive a sense of enchantment, wonder, and magic through the backdoor of geoengineering.

Operationalized in the 1950s, the modification of weather through the technique of cloud seeding - the sprinkling of chemical elements such as silver iodine and carbon dioxide into the atmosphere-is a nonenchanted technique of microclimatic geoengineering. While its weaponization has since been banned, efforts to chemically control the weather continue apace today.

Behind this form of elemental control are chemists and meteorologists who played the role of secular rainmakers. Take Irving Langmuir and Vincent Shaefer. The duo first developed the method of artificial seeding of clouds to induce precipitation while working for the General Electric Research Laboratory during World War II, and they later continued this development for classified US military weather modification projects during the Cold War (Harper and Doel 2010, 118; see also Fleming 2010). As evident in the US military's attempted use of cloud seeding during the Vietnam War to generate tropical storms and prolong the monsoon season in order to disrupt the ground logistics of the North Vietnamese, elemental control of wind and rain was central to the weaponization of the weather (Furuhata, 2019; see also Edwards 2010). In this case, the scientific knowledge of chemistry and meteorology rather than the cosmological knowledge of natural forces was required. This particular practice of weather control, moreover, hinged on another decisive technological development of the mid-twentieth century: the invention of digital computers. At this point, the history of computing dovetailed with that of elemental control.

The US Navy provided the initial funds to support physicist John von Neumann and meteorologist Jule Charney's experiment with computerized weather prediction at the Institute for Advanced Study in Princeton with the hope that the precise prediction of weather would lead to its eventual modification (Edwards 2010, 112). This coupling of prediction and control of the weather through digital computers and cloud seeding marks a moment when chemical elements became the direct medium of controlling natural elements of the weather. Chemistry, meteorology, and computation came 
together to foster a wild dream of controlling wind and rain at will. ${ }^{2}$ In short, the epistemological framework of modern chemistry was necessary for the development of the nonenchanted technique of weather control.

Put differently, my argument is that the computationally supported geoengineering practice of weather control points to the primacy of chemical elements (such as silver and iodine) over classical elements (such as water and fire) for conceptualizing the elemental nature of media as cultural techniques. Although this distinction between natural elements and chemical elements often gets elided in writing about elemental media, it is worth underscoring its historical importance.

\section{ALCHEMY, DIVINATION, COMPUTATION}

That said, however, it is medieval European alchemy rather than modern chemistry that has recently made an intriguing entry into media studies. Alchemy bridges the Greek philosophy of classical elements and the modern science of chemical elements. The work of media scholars such as Jussi Parikka, Nicole Starosielski, Kate Crawford, and Vladan Joler has foregrounded alchemy as a metaphor to understand the material reliance of computational media on the extraction and manipulation of precious metals and other geological matters (Parikka 2017; Starosielski 2016; see also Crawford and Joler 2018). There the analogy of alchemic transmutation of mineral elements-rather than the Greek philosophy of classical elements-takes central stage. What the analogy of alchemy seems to provide are the cultural connotations of enchantment, experimentation, and mystery associated with computation as well as the extractive processes of mining, smelting, refining, and controlling metallic and mineral elements.

For instance, Parikka turns to the sixteenth-century alchemic philosophy of Paracelsus in his discussion of digital alchemy. In so doing, he shifts our attention away from "a world of wizardry, of all sorts of technological operations pertaining to software as an immaterial regime of things conjured from nowhere," to "the new alchemies of corporate digital culture," which operationally relies on the material production of rare earth minerals (Parikka 2017, 342).

As Parikka's evocation of software wizardry indicates, the mythological language of enchantment-wizardry, sorcery, magic, animism, and divination-has been associated with digital media for some time. From Wendy Chun's seminal analysis of source code as sorcery to Fenwick McKelvey's discussion of the digital daemons that manage the Internet, studies of digital and computational media have a special affinity with enchanted objects and techniques of enchantment that the scientific rationality of secular

\footnotetext{
2 Many of the Japanese meteorologists who worked for military research during World War II were recruited to American institutions and joined Cold War meteorological projects in the 1950s. See Furukawa (2015).
} 
modernity supposedly has left behind (Chun 2008; McKelvey 2018; Marenko 2014). Contrary to Max Weber's dictum about the disenchantment of the modern world, the contemporary discourse of computation is clearly enchanted.

Compounding this residual aura of enchantment surrounding computational media is a curious nexus between cybernetics and the Chinese divination system. Were we to trace a genealogy of modern computing beyond the Turing machine and further back to the mathematical system of binary numbers, we inevitably arrive at German mathematician Gottfried Wilhelm Leibniz, a person whom Norbert Wiener called the patron saint of cybernetics. As Lydia Liu argues, Leibniz was interested in the ancient Chinese text of I Ching (or Yijing) and its system of divination based on eight trigrams (bagua). Each individual trigram (kua) is in turn composed of different combinations of the binary code of the yin and the yang. Leibniz saw a parallel logic of his binary calculus based on zeros and ones in this Chinese system of divination. ${ }^{3}$

Although Leibniz's engagement with China and the genealogical relevance of divination to the modern practices of statistically based prediction, computation, and cybernetics are outside the scope of this essay, I bring up this minor linkage between the eight trigrams and the history of computation since through this linkage, we see an anachronistic encounter between the Eastern philosophy of elements and the digital computer-and thereby witness the genealogical entanglement of distinct lineages of elemental philosophy.

Arguably, then, the Eastern philosophy of elements that continues to animate the enchanted cultural techniques of elemental control is already a part of the complicated genealogy of Western media, including computation and cybernetics. If that is the case, the nonenchanted technique of modifying the weather, developed by chemists, meteorologists, and computer scientists, is not, in fact, as distant from the enchanted techniques of controlling the wind through dragon holes and iron sickles as one would otherwise think. Both forms of elemental control operate like wizardry, are driven by the desire to manipulate the environment, and are connected by the logic of binary codes.

\section{CONCLUSION}

To conclude, the philosophy of elemental media is deeply entangled with geopolitics. This entanglement should encourage us to question the takenfor-granted centrality of Western philosophical and cosmological thought that undergirds our discussions of elements in media studies. And yet it should also caution us not to exoticize, homogenize, or Orientalize Eastern philosophy and cosmological thought. After all, there are myriad local interpretative

\footnotetext{
3 According to Liu, Leibniz's philosophical investment in I Ching was later passed on to Lacan, who studied Chinese and developed his own system of binary codes under the influence of Wiener's cybernetics. (Liu 2010, 309; see also Perkins 2004; Williams 2016.)
} 
differences, historical transformations, and political appropriations within East Asia of what I have heuristically presented here as an Eastern philosophy of elements. ${ }^{4}$

The geopolitical complexities and environmental impact of geoengineering-from the mining of geological materials from the earth to weaponization of weather control-also suggest that we cannot dissociate the political economy of mineral extraction and warfare from the historically and locally situated knowledges and techniques of elemental control. In other words, the geo (literally "earth") of geopolitics matters. That is to say, the politics of geographically delineated territories, as well as the material conditions of geology, need to be rethought in relation to how "earth" is cosmologically conceptualized. The challenge of thinking elemental media philosophically is to attend to these distinct cosmologies and their geopolitics.

This is an open-access article distributed under the terms of the Creative Commons Attribution 4.0 International License (CCBY-4.0). View this license's legal deed at http://creativecommons.org/licenses/ by/4.0 and legal code at http://creativecommons.org/licenses/by/4.0/legalcode for more information. 


\section{REFERENCES}

Chinese University of Hong Kong, Department of Architecture. 2005. "Feasibility Study for Establishment of Air Ventilation Assessment System.” https://www.pland.gov.hk/pland_en/ p_study/comp_s/avas/papers\%26reports/final_report.pdf.

Chun, Wendy Hui Kyong. 2008. “On ‘Sourcery,' or Code as Fetish.” Configurations 16 (3): 299-324. https://doi.org/10.1353/con.0.0064.

Crawford, Kate, and Vladan Joler. n.d. “Anatomy of an AI System.” Accessed September 7, 2019. https://anatomyof.ai/.

Edwards, Paul N. 2010. A Vast Machine: Computer Models, Climate Data, and the Politics of Global Warming. Cambridge, MA: MIT Press.

Fleming, James Rodger. 2010. Fixing the Sky: The Checkered History of Weather and Climate Control. New York: Columbia University Press.

Furuhata, Yuriko. 2019. "The Fog Medium: Visualizing and Engineering the Atmosphere.” In Screen Genealogies: From Optical Device to Environmental Medium, edited by Craig Buckley, Francesco Casetti, and Rüdiger Campe. Amsterdam: Amsterdam University Press.

Furukawa, Takehiko. 2015. Kishōchō Monogatari: Tenki Yohō Kara Jishin, Tsunami, Kazan Made [A Tale of the Japan Meteorological Agency: From Weather Prediction to Tsunami and Volcanic Explosions]. Tokyo: Chūkō shinsho.

Harper, Kristine C., and Ronald E. Doel. 2010. "Environmental Diplomacy in the Cold War: Weather Control, the United States, and India, 1966-1967.” In Environmental Histories of the Cold War, edited by J.R. McNeill and Corinna R. Unger, 115-38. Cambridge: Cambridge University Press.

Hui, Yuk. 2016. The Question Concerning Technology in China: An Essay in Cosmotechnics. Falmouth, UK: Urbanomic.

Keegan, Matthew. 2018. "Hong Kong: The City Still Shaped by Feng Shui." Guardian, July 19, 2018. https://www.theguardian.com/cities/2018/jul/19/hong-kong-the-city-still-shaped-by-fengshui.

Liu, Lydia H. 2010. “The Cybernetic Unconscious: Rethinking Lacan, Poe, and French Theory.” Critical Inquiry 36 (2): 288-320. https://doi.org/10.1086/648527.

Lo, Andrea. 2018. "The Truth behind the Mysterious Holes in Hong Kong's High-Rises.” CNN, March 28, 2018. https://www.cnn.com/style/article/hong-kong-skyscrapers-with-holes/ index.html.

Marenko, Betti. 2014. "Neo-Animism and Design: A New Paradigm in Object Theory." Design and Culture 6 (2): 219-41. https://doi.org/10.2752/175470814x14031924627185.

McKelvey, Fenwick. 2018. Internet Daemons: Digital Communications Possessed. Minneapolis: University of Minnesota Press. https://doi.org/10.5749/9781452961743.

Parikka, Jussi. 2017. “The Alchemic Digital, the Planetary Elemental.” In Subcommunity: Diabolical Togetherness beyond Contemporary Art: E-Flux Journal, edited by Julieta Aranda, Brian Kuan Wood, and Anton Vidokle, 341-47. London: Verso.

Perkins, Franklin. 2004. Leibniz and China: A Commerce of Light. Cambridge: Cambridge University Press. https://doi.org/10.1017/cbo9780511519994. 
Peters, John Durham. 2015. The Marvelous Clouds: Toward a Philosophy of Elemental Media. Chicago: University of Chicago Press. https://doi.org/10.7208/chicago/9780226253978.001.0001.

Siegert, Bernhard. 2015. Cultural Techniques: Grids, Filters, Doors, and Other Articulations of the Real. Translated by Geoffrey Winthrop-Young. New York: Fordham University Press. https://doi.org/10.2307/j.ctt14jxrmf.

Starosielski, Nicole. 2016. "Thermocultures of Geological Media." Cultural Politics 12 (3): 293-309. https://doi.org/10.1215/17432197-3648858.

-_-. 2019. "The Elements of Media Studies." Media+Environment 1.

Williams, R. John. 2016. "World Futures.” Critical Inquiry 42 (3): 473-546. https://doi.org/ $\underline{10.1086 / 685603 .}$.

Yoshino, Hiroko. 1983. Inyō Gogyō to Nihon No Minzoku [Yin-Yang Five Elements and Japanese Folk Traditions]. Kyoto: Jinbun shoin. 